\title{
An Electrospray Ionization Source for Thermochemical Investigation with the Guided Ion Beam Mass Spectrometer
}

\author{
R. M. Moision and P. B. Armentrout \\ Department of Chemistry, University of Utah, Salt Lake City, Utah, USA
}

\begin{abstract}
An electrospray ionization (ESI) source developed for use with the guided ion beam tandem mass spectrometer (GIBMS) is described. For accurate determination of thermochemistry using threshold collision-induced dissociation (TCID), it is essential that any source produces ions with four exacting characteristics: (1) high intensity, (2) stable signal, and well-defined energies both (3) kinetic, and (4) internal. To accomplish these objectives, the ions generated by the electrospray are collected using a radio frequency electrodynamic ion funnel and are then transferred into a hexapole ion guide where they are thermalized and subsequently passed into higher-vacuum regions for analysis. The resulting ion intensities using this source can exceed $10^{6}$ ions/s. Stable beams ( $<10 \%$ variation in signal) can be generated over multiple hours. The kinetic energy distribution of ions emerging from this source has been shown to be well described by a Gaussian distribution with a full width half maximum (FWHM) of about $0.1-0.2 \mathrm{eV}$ in the laboratory frame of reference. Finally, TCID results for ions generated with this source show excellent agreement with previously reported threshold values for ions generated using a variety of sources and experimental methodologies. This confirms that internal energies of the ions are well described by a Maxwell-Boltzmann distribution at room temperature. (J Am Soc Mass Spectrom 2007, 18, 1124-1134) (C) 2007 American Society for Mass Spectrometry
\end{abstract}

S ince its introduction in the 1980s [1], electrospray ionization (ESI) has become a widely used source for mass spectrometry. The popularity of the ESI can be credited to a number of factors. In addition to its ability to gently transfer large biological molecules into the gas phase in multiple charge states, ESI sources benefit from being simple in design and robust in use. However, despite its widespread acceptance, the ESI source has been used in only a limited number of experiments for quantitative determination of thermochemical information [2-6]. This is unfortunate, given the ability of the ESI to easily produce a large number of interesting gas-phase biological ions [7-9], charged transition metals [10-12], and alkali metal/ligand complexes [12-14]. The scarcity of thermochemical data originating from the ESI most likely lies in the difficulty of producing an ion beam that is suitable for rigorous thermochemical analysis. These prior ESI studies [2-6], where simpler ESI sources have been used to generate ions, have not thoroughly demonstrated whether such conditions (outlined below) have been reached.

Threshold collision-induced dissociation (TCID) experiments represent a well-established means of obtaining accurate thermochemical data for a diverse range of

Address reprint requests to Prof. Peter B. Armentrout, University of Utah, Department of Chemistry, 315 S 1400 E, Room 2020, Salt Lake City, UT 84112. E-mail: armentrout@chem.utah.edu gas-phase ions [15-20]. Essentially, TCID consists of systematically varying the kinetic energy of a mass selected ion beam and then colliding the ions with a stationary non-reactive gas such as xenon. With increasing collision energy, the parent ion begins to fragment into products that are then collected as a function of the collision energy. The resulting data may be modeled to determine the absolute minimum, or threshold, energy necessary for each fragmentation pathway. Clearly, to rigorously quantify the threshold energy required for fragmentation, the kinetic and internal energy of the ions-before collision with the stationary gas-must be known.

One of the challenges in the development of a source suitable for TCID experiments is that it must produce ions with well-defined internal and kinetic energies in addition to the more conventional requirements of any source, good stability, and high intensity. Importantly, once the ions are created, the ion beam must be characterized to verify that the kinetic and internal energy distributions are well defined. In the vast majority of mass spectrometry applications using an ESI, one or possibly two of these demands might be required of the source, but rarely must an ESI source simultaneously satisfy all of these considerations. Here we describe the development of an ESI source suitable for quantitative threshold determination using the GIBMS. 


\section{Experimental}

\section{The GIBMS}

The guided ion beam mass spectrometer (GIBMS) instrument, data collection, and subsequent data analysis have been described in detail on a number of previous occasions and will be only briefly described here $[15,16$, $19,21]$. Ions produced in the source region are initially mass selected in a magnetic momentum analyzer. The mass selected ions are decelerated to a well-defined kinetic energy and are focused into a radio frequency (rf) octopole ion guide that traps the ions radially [22, 23]. For TCID experiments, the octopole passes through a static gas cell containing xenon. After passing through the collision cell, any product ions and the remaining reactant ions drift to the end of the rf octopole where they are mass analyzed using a quadrupole mass filter and processed using standard counting techniques.

Ion intensities, measured as a function of collision energy, are converted to absolute cross sections using a Beer's Law relationship [21]. The absolute zero of energy for the ion beam is determined using a retarding potential technique by systematically varying the DC voltage on the octopole. The derivative of the onset energy is fit to a Gaussian distribution with the center of the fit defining the zero of kinetic energy $\left(\mathrm{KE}_{0}\right)$ of the ion beam and the full width at half maximum (FWHM) of the distribution describes the kinetic energy spread. Ion kinetic energies in the laboratory frame (Lab) are converted to energies in the center-of-mass $(\mathrm{CM})$ frame using $E_{\mathrm{CM}}=$ $E_{\mathrm{Lab}} m /(m+M)$, where $M$ and $m$ are the masses of the ionic and neutral reactants, respectively.

Most data presented herein are compared to a DC discharge/flow tube source (DC/FT) which has been used for a large number of studies in this laboratory $[16-19,24]$ and others [25-27]. The DC/FT source has been well described and has produced thermochemistry for a vast array of systems that is consistent with other experimental methodologies as well as ab initio calculations. Thermalization of the ions' internal modes in the DC/FT is accomplished by roughly $10^{5}$ collisions between the ions and the helium bath gas as they pass through a nearly $140-\mathrm{cm}$-long flow tube at room temperature $(\sim 300 \mathrm{~K})$. This results in the ions acquiring internal energies (rotational and vibrational) that are well described by a Maxwell-Boltzmann distribution at $300 \mathrm{~K}$. One of the limitations of the DC/FT is that solid samples (e.g., amino acids) must be introduced into the gas phase by gentle heating. For many of these samples, the temperatures required to generate sufficient vapor pressure of the solid necessary to produce a high intensity ion beam often result in decomposition of the molecule being favored over vaporization. This effect either limits the intensity of the resultant ion beam of interest or can lead to non-thermalized ions or ions of different structure than anticipated.

\section{Thermochemical Analysis}

Modeling of the threshold regions of the CID reaction cross sections using the GIBMS have been described previously [20, 21, 28]. In short, the cross sections are modeled using the following equation:

$$
\sigma(E)=\sigma_{0} \sum_{i} g_{i}\left(E+E_{i}-E_{0}\right)^{n} / E
$$

where $\sigma_{0}$ is an energy-independent scaling factor, $n$ is an adjustable parameter that characterizes the efficiency of collisional energy deposition [20], $E$ is the relative kinetic energy of the reactants in the center of mass frame, and $E_{0}$ is the threshold for CID of the ground electronic and rovibrational state of the reactant ion. The summation is over the rovibrational states of the reactant ions $i$, where $E_{\mathrm{i}}$ is the excitation energy of each state and $g_{\mathrm{i}}$ is the fractional population of those states $\left(\sum g_{\mathrm{i}}=1\right)$. Before comparison with experimental data, eq 1 is convoluted to account for the kinetic energy of the reactant ion and thermal broadening of the neutral gas $[29,30]$.

Multiple reactant ion/neutral collisions can systematically obscure the interpretation of data resulting in extracted threshold energies being inaccurately low. For this reason, the pressure of xenon in the collision cell is deliberately kept low (0.04-0.12 mTorr). In this range of pressures, the probability of an ion undergoing a single collision is roughly $4-10 \%$. Therefore, the majority of parent ions $(>90 \%)$ pass through the collision cell without any interaction with the neutral gas. All data are collected at multiple collision pressures (usually $0.04,0.08$, and 0.12 mTorr) and the resulting cross sections are extrapolated to $0 \mathrm{mTorr}$, giving rigorous single collision conditions for analysis.

A further consequence of the requirement for low collision cell pressures is that the intensities of product channels with small reaction probabilities can be close to or below the signal-to-noise ratio of the instrument. Because these lesser reaction channels often provide the most interesting information about a TCID reaction, it is of great value to have a parent ion beam with the greatest possible intensity. With a parent ion beam of $10^{5}$ ions/s and collision gas pressure of 0.10 mTorr, a cross section of $0.1 \times 10^{-16} \mathrm{~cm}^{2}$ is produced from a product ion intensity of $25 \mathrm{ions} / \mathrm{s}$, close to the sensitivity level of the GIBMS. Therefore, a reactant ion beam intensity of about $10^{5}$ ions/s is sufficient for collecting accurate information on the majority of product channels and intensities of $10^{4}$ ions/s allow major products to be scrutinized carefully.

For the ions that do undergo a collision, the energy imparted is efficiently randomized into internal modes, making dissociation increasingly inefficient for larger molecules. As a result, post-collisional ions with internal energies above the threshold energy may not dissociate during the timescale of the experiment, about $5 \times 10^{-4} \mathrm{~s}$. This results in an observed threshold with an onset delayed by a kinetic shift that increases as the size 


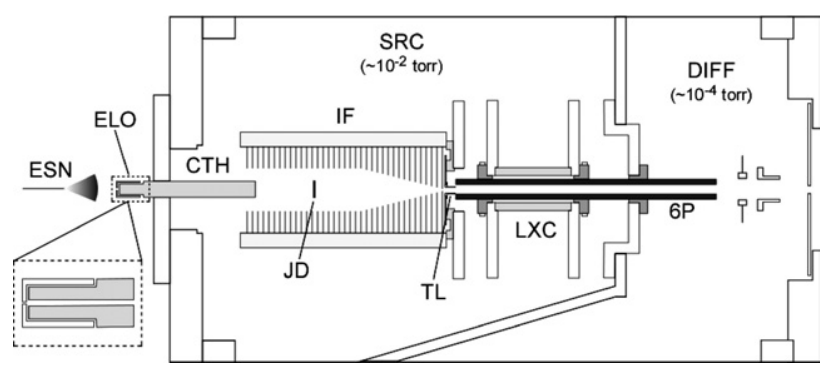

Figure 1. Schematic diagram of the electrospray ionization source designed for the guided ion beam tandem mass spectrometer (GIBMS). The electrospray needle (ESN), consisting of 35gauge stainless steel tubing. ESI ions are transferred into the first vacuum region, SRC $\left(\sim 10^{-2}\right.$ Torr), through 0.030 -in.-ID capillary tubing held in place by the capillary tubing holder $(\mathrm{CTH})$. Ions are collected by the ion funnel (IF) and transferred into a hexapole (6P) by a tube lens (TL). The 6P passes through the ligand exchange cell (LXC) before entering the first differentially pumped region (DIFF; $\sim 10^{-4}$ Torr). Large vertical plates shown are used to support the lens train on three rods (not shown).

of the molecule becomes larger. Rice-Ramsperger-Kassel-Marcus (RRKM) statistical theory is incorporated into eq 1 to estimate these kinetic shifts [31]. For the $\mathrm{H}_{3} \mathrm{O}^{+}\left(\mathrm{H}_{2} \mathrm{O}\right)_{n}$ clusters discussed below, these kinetic shifts are small (0.01-0.06 eV). For the larger $\mathrm{Na}^{+}$(proline) system, which contains more vibrational modes and has a higher threshold, the shifts are slightly larger $(\sim 0.15 \mathrm{eV})$.

\section{Electrospray Ionization Source}

A schematic overview of the electrospray ionization/ ion funnel/hexapole (ESI/IF/6P) source appears in Figure $1 .{ }^{\circ}$ Solutions ${ }^{\circ}$ containing ${ }^{\circ}$ the ${ }^{\circ}$ ions ${ }^{\circ}$ of $^{\circ}$ interes $t^{\circ}$ are prepared at concentrations of $10^{-4}-10^{-5} \mathrm{M}$ [e.g., $10^{-5} \mathrm{M}$ proline $+10^{-5} \mathrm{M} \mathrm{NaCl}$ for $\mathrm{Na}^{+}$(proline)]. Solutions are introduced using a syringe pump (Model 55-1111; Harvard Apparatus, Holliston, MA, USA) at flow rates of 0.01-0.10 mL/h (170-1700 nL/min). Electrospray needles (ESN) are prepared from 35-gauge, regular-wall, hypodermic stainless steel tubing (Small Parts, Miami Lakes, FL, USA). The needles are biased at 1300-2100 V relative to ground. The entire needle assembly is mounted on an XYZ translation stage that allows for fine-tuning of the location of the needle relative to the vacuum entrance orifice.

Ions emanating from the spray are transferred into the vacuum region by a short length $(\sim 4.0$-in.) of 0.063-in. (1/16-in.) OD stainless steel capillary tubing. Such tubing is readily available from a number of HPLC suppliers and comes with standard ID values ranging from 0.010 - to 0.040 -in. ID Tubing of $0.030 \mathrm{in}$. ID is used in experiments described here. The 0.063-in./capillary tubing is held within a capillary tubing holder (CTH). The CTH is machined from 0.375-in.-OD/0.063-in.-ID tubing (High Pressure Equipment Company, Erie, PA, USA), which is reamed out to an ID of $0.067 \mathrm{in}$. to allow for insertion of the 0.063 -in.-OD stainless steel capillary tubing. This design allows for different lengths and ID values of capillary tubing to be used and for the tubing to be changed without the need to vent the entire instrument.

The CTH is centered and electrically isolated using fittings made of PEEK thermoplastic. This permits the entire capillary to be biased independently and heated to $>200{ }^{\circ} \mathrm{C}$ if necessary. The temperature of the $\mathrm{CTH}$ assembly is controlled using heating tape and a temperature controller (Model T16; Red Lion Controls, York, PA, USA) and the temperature monitored using a thermocouple. In normal operation, the temperature of the capillary is $50-150{ }^{\circ} \mathrm{C}$ and the entire assembly is generally biased at $25-50 \mathrm{~V}$ relative to ground.

The entrance to the 0.063 -in.-OD capillary tubing is further restricted using an entrance limiting orifice (ELO) that is machined into a cap that slides over the entrance end of the CTH (which is machined to an OD of 0.250 in. to secure and center the cap). The ELO cap is machined from 0.375 -in.-OD stainless steel rod that is reamed to an ID of 0.251 in. to a depth that leaves an end wall thickness of about 0.040 in. A small-diameter hole (0.006-0.015 in.) is drilled through the center such that this hole is centered with respect to the 0.063in.-OD capillary tubing when the ELO is in place on the CTH. For capillary tubing IDs from 0.020 to 0.040 in., we have tested ELOs ranging in size from 0.006 to 0.020 in. and have found that when the diameter of the entrance hole is less than one half of the ID of the capillary tubing, the signal stability is greatly improved. Even with the smallest-diameter hole (0.006 in.) used to date, we have observed this enhanced stability without any loss of signal intensity. The ELO serves to throttle the gas load into the vacuum such that the diameter of the ELO is directly correlated to the pressure in the source region. We believe that the ELO also functions to hydrodynamically focus the gas into the center of the capillary tubing.

The lens train within the source region (SRC) is supported and centered using three 0.250 -in. centerless ground stainless steel rods on a 3.50-in. BC. The rods are centered with respect to the vacuum chamber on both ends. This allows all of the components on the lens train to be centered radially within $0.004 \mathrm{in}$. with respect to each other. These support rods have been removed from ${ }^{\circ}$ Figure $^{\circ} 1^{\circ}$ for $^{\circ}$ clarity..$^{\circ}$ The $^{\circ}{ }^{\circ} C^{\circ}{ }^{\circ}$ region ${ }^{\circ}$ of ${ }^{\circ}$ the ${ }^{\circ}$ instrument is pumped by a $300 \mathrm{~L} / \mathrm{s}$ roots blower (Model EH 1200; Edwards High Vacuum, Sussex, UK) backed by a mechanical pump (Edwards model E2M175). The lens train continues into a differentially pumped region (DIFF). This region is pumped by an $1800 \mathrm{~L} / \mathrm{s}$ diffusion pump (Model VHS-6; Varian, Inc., Palo Alto, CA, USA) backed by a mechanical pump (Varian model SD-451).

\section{Ion Funnel}

The ion funnel (IF) is based largely on the design of Smith ${ }^{\circ} t^{\circ}{ }^{\circ}{ }^{\circ}[32,33] .{ }^{\circ}$ Briefly, ${ }^{\circ}$ the ${ }^{\circ}$ ion ${ }^{\circ}$ funnel ${ }^{\circ}$ consists $^{\circ}{ }^{\circ}{ }^{\circ} a$ stack of electrically isolated ring electrodes (or plates) 
with decreasing inner diameters in the direction of the exit. Each plate receives a signal consisting of a combination of rf and DC voltages. Equal and opposite phases of the rf signal are applied to adjacent plates. This oscillating field on the plates in conjunction with the physically tapering lenses focuses the ions radially into the center of the ion funnel. The out-of-phase rf signals oscillate symmetrically about a DC potential applied to each plate. From entrance to exit, the plates receive a linearly decreasing DC voltage. This DC voltage gradient helps to "pull" positively charged ions through the ion funnel. The combination of electric fields and physical geometry has been shown to give transmission efficiencies nearing unity at ${ }^{\circ}$ pressures up to $10^{\circ}$ Torr [34]. This makes the ion funnel an ideal candidate for accepting the rapidly diverging ions emanating from an ESI capillary.

The plates for the ion funnel are machined from 0.020-in.-thick brass sheets into $1.625 \times 1.625$-in. squares with small tabs $(0.1 \times 0.1$-in. $)$ centered on two sides to allow for convenient electrical connections. These tabs are similar in size to the Smith design, although they are not used with their custom-made zero-insertion-force (ZIF) sockets. Rather, each plate is soldered to a 1-in. length of 28-gauge prestripped wire-wrap wire. The wires are then individually connected to the circuit board described below. This results in a rather tedious initial setup, but produces robust connections and allows for multiple configurations of ion funnel to be quickly assembled and tested. Each plate is electrically and physically separated from its neighbors using 0.020 -in.-thick Teflon ${ }^{\circledR}$ sheet cut into $1.625 \times 1.625$-in. squares with an ID of 1.125 in. For the brass plates, the ID of the first 44 plates was held at 1.00 in. and the final 44 plates formed a linear taper from 1.00 in. to a final ID of 0.094 in. To align the plates relative to the ion funnel central axis, all plates and Teflon ${ }^{\circledR}$ spacers have four 0.252 -in. holes on a 1.625-in. radius. The stack of brass plates and Teflon ${ }^{\circledR}$ spacers are then assembled onto four 0.250 -in. ceramic tubes. For mounting and compressing the IF, lengths of 4-40 threaded rod pass through the four ceramic tubes. The threaded rods are fastened to a mounting plate that is secured and centered using the main support rods.

In total, 88 lenses are used in the ion funnel, making the overall length just under $4 \mathrm{in}$. Approximately 1 in. from the ion funnel inlet is an electrically isolated 0.25-in.-diameter ${ }^{\circ}$ etal $^{\circ}$ disc $^{\circ}$ or $_{\text {Get }}^{\circ} \operatorname{disrupter}^{\circ}(J D)$ [35, 36]. This disc helps to prevent large solvent clusters from depositing further downstream on the hexapole (6P) and does not lead to a decrease in signal intensity for the mass range of ions investigated to date. Such deposits on the $6 \mathrm{P}$ can lead to electrostatic barriers being formed, which result in ion trapping and ultimately poorly defined kinetic energies and non-thermal internal energy distributions.

As mentioned earlier, each plate requires a combined rf and DC signal. We have designed our own custom circuit board using an inexpensive internet vendor
(www.ExpressPCB.com).$^{\circ} \mathrm{A}^{\circ}$ single ${ }^{\circ}$ circuit $^{\circ}$ board $^{\circ}$ contains both $\mathrm{rf}$ and $\mathrm{DC}$ circuits, thus requiring only one electrical connection per plate $(1 / 2$ that of the Smith design). Surface-mount resistors (200 kOhm, 1/8 Watt, Size 1206, Allied Electronics, Fort Worth, TX, USA) and capacitors (0.01 $\mu \mathrm{F}, 100 \mathrm{~V}$, Size 1206, Allied Electronics) are used on the board. The linear voltage gradient across the plates is defined by DC voltages on the entrance $\left(\mathrm{DC}^{+}\right)$and exit $\left(\mathrm{DC}^{-}\right)$ends of the resistor chain. General ion funnel conditions are $\mathrm{DC}^{+}=15 \mathrm{~V}$ (ion funnel entrance or upstream voltage) and $\mathrm{DC}^{-}=5$ $\mathrm{V}$. The voltage on the jet disrupter is independently adjusted and typically gives optimum signal when it is close to that of $\mathrm{DC}^{+}$. Therefore its voltage must be optimized each time the $\mathrm{DC}^{+}$or $\mathrm{DC}^{-}$values are adjusted. The rf voltage is about $25 \mathrm{~V}$ peak to peak (Vpp) at a frequency of $1.2 \mathrm{MHz}$.

The rf signal is applied to the ion funnel using a sine-wave output from a signal generator (Model 33120A; Hewlett-Packard, Palo Alto, CA, USA) and is amplified with an rf amplifier (Model 2100L; ENI, Rochester, NY, USA). The signal from the amplifier is split into equal and opposite phases with a 50-ohm trifilar-wound ferrite-core balun transformer. The balun consists of two stacked FT-290 toroids (Amidon Associates, Costa Mesa, CA, USA) wrapped with 14-gauge magnet wire. We have found that the opposite phase signals generated when the balun is wrapped as a trifilar are more equally balanced relative to a bifilar design. This circuit is capable of driving an 88-plate ion funnel at roughly $50 \mathrm{Vpp}$ at $1 \mathrm{MHz}$ and $20 \mathrm{Vpp}$ at 2 $\mathrm{MHz}$.

A DC tube lens (TL) is placed at the interface between the ion funnel and hexapole. The tube lens is created from a modified IF plate having a central hole with an ID of 0.14 in. onto which a tube having an OD of $0.17 \mathrm{in}$. and a length of $0.15 \mathrm{in}$. is attached. It is physically separated from the final ion funnel plate using a single Teflon ${ }^{\circledR}$ spacer described earlier. The lens is inserted $0.05-0.10 \mathrm{in}$. into the $6 \mathrm{P}$ and is biased between the $\mathrm{DC}^{-}$voltage of the ion funnel and the $6 \mathrm{P}$ bias $(0 \mathrm{~V})$. At the operating pressures in the ion funnel, this lens has little focusing effect on the ions. However, it probably helps to prevent ions that have entered the $6 \mathrm{P}$ from diffusing back upstream toward the IF.

\section{rf Heating in the IF}

Initial efforts involved a configuration where ions exited the ion funnel directly into the DIFF region without the $6 \mathrm{P}$ present, ESI/IF. Although this arrangement produces excellent intensities and reasonable kinetic energy distributions, using the IF without subsequent thermalization steps can result in ions picking up internal energy in excess of thermal temperatures, i.e., the internal energies of the ions are no longer well described by a Maxwell-Boltzmann distribution at room temperature. The internal energies may still be satisfactorily described using a higher temperature dis- 
tribution, but this temperature is now either unknown or poorly defined and dependent on experimental conditions.

Figure $2^{\circ}$ shows ${ }^{\circ}$ the ${ }^{\circ} \mathrm{CID}^{\circ}$ cross $^{\circ}$ section ${ }^{\circ}$ of ${ }^{\circ}$ the ${ }^{\circ} \mathrm{Na}^{+}{ }^{\circ}$ loss from $\mathrm{Na}^{+}$(proline) produced by the ESI/IF source described earlier at two different rf voltages applied to the IF, Vpp. For reference, CID results for the same system are shown with the ions generated using a DC/FT source. Clearly, the onset energy of the $\mathrm{Na}^{+}$shifts to lower energies as the IF Vpp increases. Such a shift in the threshold energy is an unambiguous symptom that the ions are being heated. In the case of the $\mathrm{Na}^{+}$(proline), at a Vpp of $30 \mathrm{~V}$, the system picks up roughly $1 \mathrm{eV}$ of internal energy. Analysis of the $\mathrm{Vpp}=$ 20 and $30 \mathrm{~V}$ results are consistent with ions having a temperature of about 500 and $700 \mathrm{~K}$, respectively. Given the scarcity of information in the literature regarding the temperature of ions produced by electrospray, it is reasonable to question the source of the internal energy increase. It is unknown whether the ions are heated exclusively by the IF or whether the ESI source also contributes.

Figure ${ }^{\circ}{ }^{\circ}$ hows ${ }^{\circ} \mathrm{Na}^{+}$(2-propanol) ${ }^{\circ} \mathrm{CID}$ results ${ }^{\circ}$ for ${ }^{\circ}$ ions produced using the DC/FT source and therefore thermalized, before being introduced into the IF. For all cases, the IF was kept at a DC voltage drop of $4 \mathrm{~V}$ and an $\mathrm{rf}$ frequency of $1.5 \mathrm{MHz}$. Changes in the rf frequency over a range of $1-2 \mathrm{MHz}$ or in the DC voltage drop across the funnel over a range of 4-20 V while holding the Vpp constant do not lead to changes in the internal energy ${ }^{\circ}$ of ${ }^{\circ}$ the ${ }^{\circ}$ ions. ${ }^{\circ}$ Figure ${ }^{\circ} 3^{\circ}$ shows $^{\circ}$ that ${ }^{\circ}$ there ${ }^{\circ}$ is ${ }^{\circ}$ little change in the threshold energy with Vpp values ranging from 5 to $14 \mathrm{~V}$ and, furthermore, the results correspond ${ }^{\circ}$ to $^{\circ}$ thermalized ${ }^{\circ}$ ions $^{\circ}[37]^{\circ}{ }^{\circ}$ However, ${ }^{\circ} a^{\circ}{ }^{\circ}{ }^{\circ} I^{\circ}{ }^{\circ} \mathrm{Vpp}$

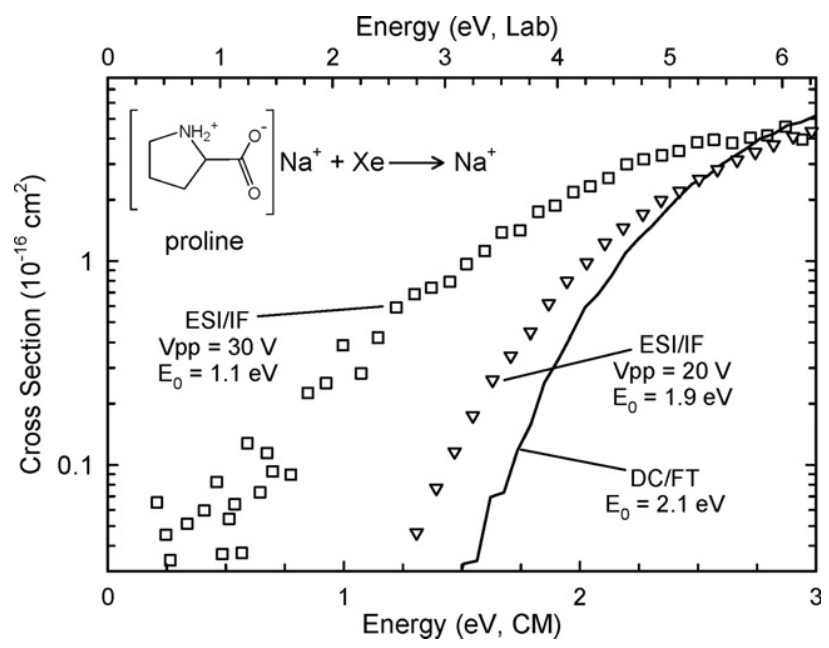

Figure 2. Cross sections for collision-induced dissociation of $\mathrm{Na}^{+}$(proline) with $\mathrm{Xe}$ as a function of kinetic energy in the center-of-mass frame (lower $x$-axis) and the laboratory frame (upper $x$-axis). The solid line shows thermalized ions produced with a DC discharge/flow tube source. Open triangles $(\nabla)$ and open squares $(\square)$ show data produced using an ESI source and ion

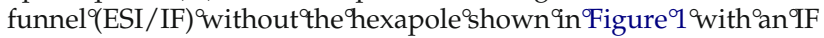
rf Vpp of 20 and $30 \mathrm{~V}$, respectively.

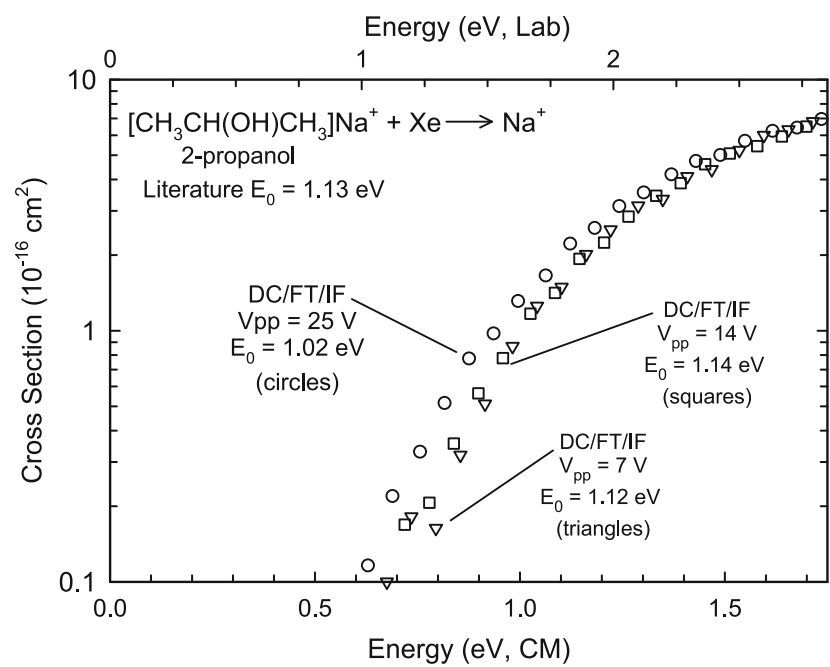

Figure 3. Cross sections for collision-induced dissociation of $\mathrm{Na}^{+}$(2-propanol) with Xe as a function of kinetic energy in the center-of-mass frame (lower $x$-axis) and the laboratory frame (upper $x$-axis). All data were produced using a DC discharge/flow tube source and ion funnel (DC/FT/IF). Open triangles $(\nabla)$ show results for the rf Vpp on the IF of $7 \mathrm{~V}$. Open squares ( $\square$ ) and open circles $(\bigcirc)$ show $\mathrm{Vpp}=14$ and $25 \mathrm{~V}$, respectively. Results at the lower ${ }^{\circ} \mathrm{Vpp}^{\circ}$ values $^{\circ}$ match $^{\circ}$ the $e^{\circ}$ literature ${ }^{\circ}[36]$.

of $25 \mathrm{~V}$, the ions clearly begin picking up internal energy $^{\circ}\left(\sim 0.1^{\circ} \mathrm{eV}\right) .^{\circ}$ The $^{\circ}$ results $^{\circ}$ in $^{\circ}$ Figures $^{\circ} 2^{\circ}$ and $^{\circ} 3$ demonstrate that the ions are picking up excess energy in the ion funnel. Although the $\mathrm{Na}^{+}$(2-propanol) does not pick up as much internal energy as the $\mathrm{Na}^{+}$(proline) at similar Vpp values, this is most likely a function of the number and magnitude of vibrational modes available in each system. It is possible that thermal ions could be produced by systematically decreasing the IF Vpp until the measured threshold ceases to exhibit signs of heating. However, lowering Vpp greatly decreases the overall signal intensity, thus defeating the purpose of the IF!

Figures ${ }^{\circ}{ }^{\circ}$ and ${ }^{\circ} 3^{\circ}$ also $^{\circ}$ provide ${ }^{\circ}{ }^{\circ}$ gauge ${ }^{\circ}$ of ${ }^{\circ}$ the ${ }^{\circ}$ sensitivity of the GIBMS for measuring and quantifying ion heating. For product ions created in the GIBMS with reasonable intensity $\left(>10^{3}\right.$ ions $\left./ \mathrm{s}\right)$, the absolute uncertainty in extracted threshold energies usually ranges from \pm 0.05 to $\pm 0.10 \mathrm{eV}$. However, much of the uncertainty in using eq 1 to model the data stems from systematically scaling the vibrational frequencies used for RRKM and internal energy calculations by $\pm 10 \%$. Therefore, when comparing relative thresholds of identical systems, the uncertainty is more akin to \pm 0.02 to $\pm 0.06 \mathrm{eV}$. For this reason, ions being heated by as little as $0.05 \mathrm{eV}$ can be clearly differentiated from thermalized ions in the GIBMS.

\section{Hexapole Ion Guide}

The hexapole ion guide (6P) consists of six 0.125-in. centerless ground stainless steel rods (Small Parts), 5.50 in. long, equally spaced on a 0.375 -in. BC. Each rod has 
0-80 tapped holes in two locations. The rods are held in place and centered using 0-80 screws inserted through a machined Torlon (a polyamide-imide thermoplastic) disc with "cups" cut out that encircle roughly $1 / 3$ of the rod diameter. Electrical connections to the rods are also made using the $0-80$ screws. The Torlon pieces attach to either end of the ligand exchange cell (LXC), which aligns the $6 \mathrm{P}$ with respect to the IF. Gases can be added to the LXC to react with ions produced by the ESI by ligand exchange or condensation. This has proven to be a useful feature for making ion complexes with ligands other than the solvent used in the electrospray process as well as creating larger ion/solvent clusters. The rf signal is applied to the rods using a simple rf generator described $^{\circ}$ by $^{\circ}$ Jones $^{\circ}$ et $^{\circ}$ al. $^{\circ}\left[38,{ }^{\circ} 39\right]^{\circ}$ and $^{\circ}$ is $^{\circ}$ normally operated at a frequency of $5.5 \mathrm{MHz}$ with a peak to peak voltage (Vpp) of 200-300 V. The DC voltage of the $6 \mathrm{P}$ is maintained at $0 \mathrm{~V}$, but can be adjusted.

One of the unique features of this $6 \mathrm{P}$ is that it spans two vacuum regions with the rods serving as the conductance limiting aperture. While running the ESI, pressures in the SRC region are approximately 20-40 mTorr and about $8 \times 10^{-5}$ Torr in the DIFF region. The gas flow between the two regions is further limited by placing a 0.5-in.-long piece of machined Torlon with cups that encircle one half of each rod. The $6 \mathrm{P}$ rods extend about $2.0 \mathrm{in}$. into the higher vacuum region. The $6 \mathrm{P}$ must be located in the higher pressure region of the instrument to provide sufficient ion/neutral collisions for thermalization. We have tried placing the hexapole solely in the higher pressure source region of the instrument with a small lens to extract the ions into the differentially pumped region. This results in a moderate loss of intensity and kinetic energy distributions that are two- to fourfold broader relative to the configuration where the hexapole spans both regions.

We have tested experimental configurations lacking the IF by injecting ions directly from the heated capillary into the $6 \mathrm{P}, \mathrm{ESI} / 6 \mathrm{P}$. This does result in signal intensities comparable to using the ion funnel, but the hexapole ${ }^{\circ}$ quickly $^{\circ}$ becomes $^{\circ}$ fouled ${ }^{\circ}$ by $^{\circ}$ spray $^{\circ}$ deposits. The most noticeable symptom of this residue is that there is a noticeable increase in the ion kinetic energy. With the ESI/6P, we have observed kinetic energies rising by $1-3 \mathrm{eV}$ in as short a time as $3-4 \mathrm{~h}$, roughly the timeframe to collect data at three to four different collision cell pressures. Under such conditions, thermalization of the ions is dubious and eventually the signal intensity for higher $\mathrm{m} / \mathrm{z}$ ions begins to significantly attenuate. With the ion funnel and jet disrupter inserted before the $6 \mathrm{P}$, kinetic energy distributions are stable for $>10$ days. From a practical perspective, this results in venting and cleaning of the hexapole on a much less frequent basis.

We have also tried placing a DC "extraction" lens on the exit side of the $6 \mathrm{P}$ where the lens inserts into the center of the 6P, similar in design to the TL at the IF/6P interface. However, use of such a lens leads to kinetic energy distributions broadened by a factor of about 3

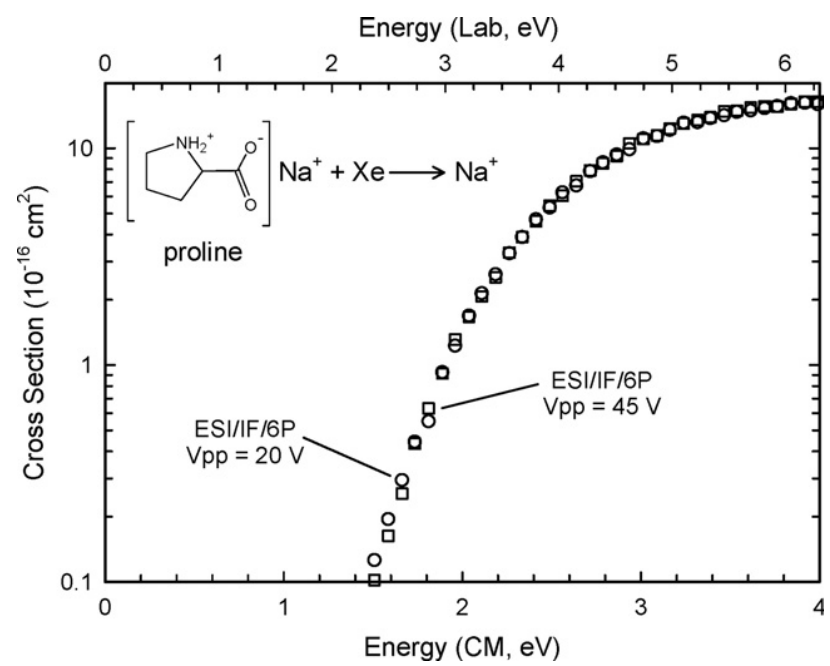

Figure 4. Cross sections for collision-induced dissociation of $\mathrm{Na}^{+}$(proline) with $\mathrm{Xe}$ as a function of kinetic energy in the center-of-mass frame (lower $x$-axis) and the laboratory frame (upper $x$-axis). Open circles $(\bigcirc)$ and open squares $(\square)$ show data produced using the electrospray/ion funnel/hexapole (ESI/IF/ $6 \mathrm{P})^{\circ}$ configuration $^{\circ}$ as $^{\circ}$ shown $^{\circ}$ in $^{\circ}$ Figure $^{\circ} 1^{\circ}$ using $^{\circ}$ an $^{\circ} \mathrm{rf}^{\circ} \mathrm{Vpp}^{\circ}$ on ${ }^{\circ}$ the ${ }^{\circ} \mathrm{IF}$ of 20 and $45 \mathrm{~V}$, respectively.

and slightly lower ion intensities. Currently, the first DC lens following the $6 \mathrm{P}$ is placed about $0.5 \mathrm{in}$. from the end of the $6 \mathrm{P}$ and has an ID of 0.375 in. and therefore minimally perturbs the ions exiting the $6 \mathrm{P}$. The ion beam emanating from the $6 \mathrm{P}$ is well collimated compared to the more diffuse beam produced by our DC/FT source. As a result, the beam intensity can be greatly attenuated if the $\mathrm{ESI} / \mathrm{IF} / 6 \mathrm{P}$ is slightly misaligned relative to the electrostatic lenses located farther down the beam line. A set of DC deflectors placed about $1 \mathrm{in}$. from the exit of the $6 \mathrm{P}$ has proven to be of great benefit for correcting any minor alignment issues.

As $^{\circ}$ with $^{\circ}$ Figure $^{\circ} 2,^{\circ}$ Figure $^{\circ} 4^{\circ}$ shows $^{\circ}$ the ${ }^{\circ} \mathrm{CID}^{\circ}$ cross section for $\mathrm{Na}^{+}$loss from $\mathrm{Na}^{+}$(proline). However, in Figure 4 a $6 \mathrm{P}$ has been ${ }^{\circ}$ added $^{\circ}$ to $^{\circ}$ the ${ }^{\circ} \mathrm{ESI} / \mathrm{IF}^{\circ}$ configuration $^{\circ}$ used $^{\circ}$ in $^{\circ}$ Figure $^{\circ} 2^{\circ}$ to ${ }^{\circ}$ reproduce ${ }^{\circ}$ the $e^{\circ} \mathrm{ESI} / \mathrm{IF} / 6 \mathrm{P}$ experimental ${ }^{\circ}$ arrangement $^{\circ}$ as $^{\circ}$ shown $^{\circ}$ in $^{\circ}$ Figure $^{\circ} 1 .^{\circ}$ The cross $^{\circ}$ sections $^{\circ}$ in $^{\circ}$ Figure $^{\circ} 4^{\circ}$ illustrate ${ }^{\circ}$ that ${ }^{\circ}$ with ${ }^{\circ}$ the ${ }^{\circ}$ addition of the $6 \mathrm{P}$, the threshold energies are independent of $\mathrm{Vpp}$ in the IF. The thresholds measured for these ions are identical to those previously published for ions generated using the DC/FT source.

As mentioned previously, the pressures in the source region of the instrument generally range from 20 to 40 mTorr (when no gas is added to the LXC). At these pressures, the mean free path of the ions is $<10 \mathrm{~mm}$. Thus, regardless of the voltage drop between the IF and $6 \mathrm{P}$, the ions quickly slow kinetically and begin to diffuse along the axis of the 6P. This leads to a high number of ion/neutral collisions in the $6 \mathrm{P}$ such that conditions in the ion funnel may be optimized for ion intensity without concern for conditions leading to non-thermal internal energy distributions. Conditions upstream from the IF, such as the temperature of the 
capillary tubing (tested over a range from 60 to $150{ }^{\circ} \mathrm{C}$ ), ESN voltage or syringe pump speed also have no impact on the thermalization of the ions.

The $^{\circ}$ experimental ${ }^{\circ}$ observations $^{\circ}$ in $^{\circ}$ Figure $^{\circ} 4^{\circ}$ were verified by simulations of the IF/ $6 \mathrm{P}$ configuration using SIMION with a realistic ion/neutral collision model [40]..$^{\circ}$ These $^{\circ}$ simulations $^{\circ}$ clearly $^{\circ}$ show $^{\circ}$ that $^{\circ}$ the $^{\circ} 6 \mathrm{P}^{\circ}$ is indeed a very efficient radial trap for ions. At pressures typically found in the source region, the ions are quickly focused to the middle of the rods by collisional cooling. Once the ions reach the center of the rods, they enter a nearly field-free region, which allows them to undergo thermalizing collisions with the neutral gas. However, it is imperative to appreciate that the hexapole provides no driving force for ions in the axial direction. This is in direct contrast to the ion funnel where the ions are pulled through by the DC voltage gradient. Placing the IF and $6 \mathrm{P}$ in series provides the opportunity to take advantage of each device while still meeting the stringent conditions necessary for an ion source used for TCID.

\section{Results and Discussion}

\section{Ion Stabilities and Intensities}

The intensity and stability of the ion beam is primarily a function of the electrospray conditions. Small changes in variables such as the solution concentration, selection of solvent, and flow rate may necessitate adjustment to the needle bias and its relative location to the entrance orifice to find optimal spray conditions.

Although the needle assembly can also be used with fused silica capillaries, 35-gauge stainless steel needles provide excellent intensity and stability for the complexes normally observed with the GIBMS. However, care must be observed when using such thin wall (0.0016-in.) tubing because small amounts of oxidation can result in the formation of minute holes. These openings can draw air into the electrospray solution within the needle, resulting in the spray flickering. The resulting instability in the ion intensity is unsuitable for TCID data collection.

Figure $^{\circ} 5^{\circ}$ shows $^{\circ} \mathrm{a}^{\circ}$ representative ${ }^{\circ} 120-\min ^{\circ}$ scan $^{\circ}$ of ${ }^{\circ}$ the $\mathrm{Na}^{+}$(proline) ion produced from a $10^{-4} \mathrm{M}$ solution of $\mathrm{NaCl}$ and proline using the ESI/IF/6P. The average intensity over the duration of the scan is $6.0 \times 10^{5}$ ions/s with a standard deviation over this period of $<5 \%$. Both the intensity and stability of this beam are comparable to other sources used with the GIBMS.

\section{Kinetic Energies}

An example kinetic energy profile for the ESI/IF/6P source $^{\circ}\left(\mathrm{Lab}^{\circ} \text { and }{ }^{\circ} \mathrm{CM}\right)^{\circ}$ is ${ }^{\circ}$ shown $^{\circ}$ in $^{\circ}$ Figure $^{\circ} 6 \mathrm{a}^{\circ}$ for $\mathrm{H}_{3} \mathrm{O}^{+}\left(\mathrm{H}_{2} \mathrm{O}\right)_{2}$ and ${ }^{\circ}$ Figure $6 b^{\circ}$ for $\mathrm{Na}^{+}$(proline). The ${ }^{\circ}$ derivative of the kinetic energy onset and its fit to a Gaussian distribution are also shown. For clarity, intensities have been normalized to unity, but the absolute intensity of both systems is approximately $1 \times 10^{6}$ ions/s.

Figure $^{\circ} 6^{\circ}$ clearly $^{\circ}$ shows $^{\circ}$ that $^{\circ}$ the ${ }^{\circ}$ derivative ${ }^{\circ}$ of ${ }^{\circ}$ the kinetic energy onset is well described by a Gaussian fit. For the $\mathrm{Na}^{+}$(proline) scan, the $\mathrm{KE}_{0}$ is $-0.39 \mathrm{eV}$ with a FWHM of $0.16 \mathrm{eV}$. The $\mathrm{H}_{3} \mathrm{O}^{+}\left(\mathrm{H}_{2} \mathrm{O}\right)_{2}$ scan shows very similar results with a $\mathrm{KE}_{0}$ of $-0.38 \mathrm{eV}$ and a FWHM of $0.14 \mathrm{eV}$. The FWHM of the kinetic energy distribution is typically $0.09-0.20 \mathrm{eV}$ in the laboratory frame of reference using the ESI/IF/6P source. For comparison, the FWHM of a one-dimensional Boltzmann velocity distribution at $300 \mathrm{~K}$ is only $0.072 \mathrm{eV}$. Thus the distortions resulting from focusing aberrations, space charge effects, and other instrumental parameters are minimized for the ESI/IF/6P source.

The FWHM values for the ESI/IF/6P are also considerably smaller than the values cited by other groups using an ESI source for TCID. Andersen et al. [2] ${ }^{\circ}$ state $^{\circ} \mathrm{FWHM}^{\circ}$ values ${ }^{\circ}$ of ${ }^{\circ} 0.6^{\circ} \mathrm{eV}^{\circ}$ for ${ }^{\circ} \mathrm{H}_{5} \mathrm{O}_{2}{ }^{+}$to $1.2 \mathrm{eV}$ for $\mathrm{H}_{9} \mathrm{O}_{4}{ }^{+}$in the laboratory frame. In later work from the $^{\circ}$ same $^{\circ}$ group $^{\circ}[4],{ }^{\circ}$ the ${ }^{\circ}$ kinetic $^{\circ}$ energ $^{\circ}$ broadening was reduced (although not quantified), at a cost of a loss ${ }^{\circ}$ f $^{\circ}$ ion ${ }^{\circ}$ intensity. ${ }^{\circ}$ Hinderling ${ }^{\circ}$ et $^{\circ}$ al. ${ }^{\circ}[5]^{\circ}$ state $^{\circ}$ values of $0.4-0.6 \mathrm{eV}$ in the laboratory frame using an ESI source. Moreover, the kinetic energy distributions produced by the ESI/IF/6P source are narrower than those produced in the DC/FT, which has FWHM values typically $0.25-0.50 \mathrm{eV}$ in the lab frame. Likely the narrow kinetic energy distributions in the ESI/ IF/6P source because the ions traverse most of the length of the $6 \mathrm{P}$ by diffusion.

As mentioned previously, a number of experiments were performed to confirm that conditions within the ion funnel do not affect the resulting kinetic energy distributions. The kinetic energy distributions produced by the ESI/IF/6P source show no dependency on the ion mass over the range of $\mathrm{m} / \mathrm{z}$ $=30-170 \mathrm{Da}$, on the Vpp of the $6 \mathrm{P}$ from 150 to $400 \mathrm{~V}$,

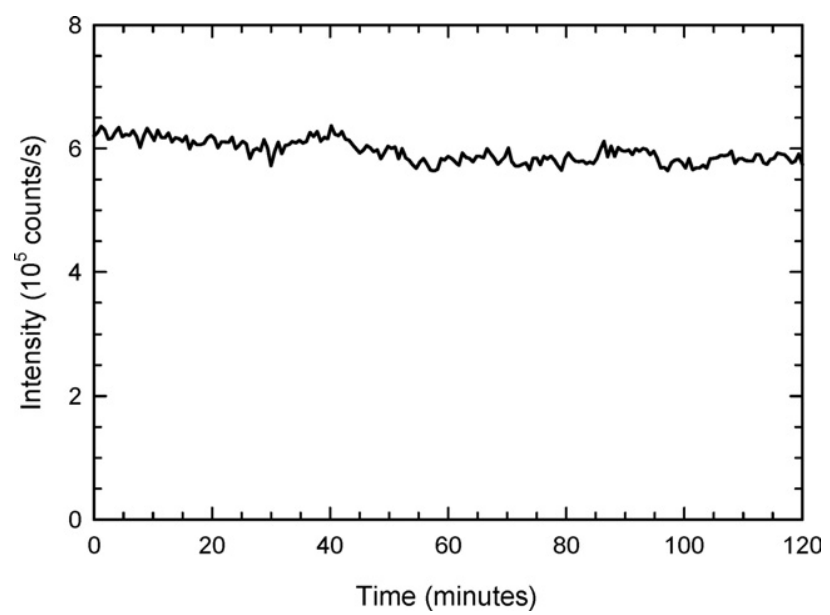

Figure 5. Stability profile of a parent ion beam produced by the ESI/IF/6P source. Scan is of $10^{-4} \mathrm{M}$ spray of $\mathrm{Na}^{+}$(proline) in a solvent of 50:50 water:methanol. Average intensity for duration of scan is $6.0 \pm 0.3 \times 10^{5}$ ions $/ \mathrm{s}$. 
$\mathrm{E}(\mathrm{CM} ; \mathrm{eV})$
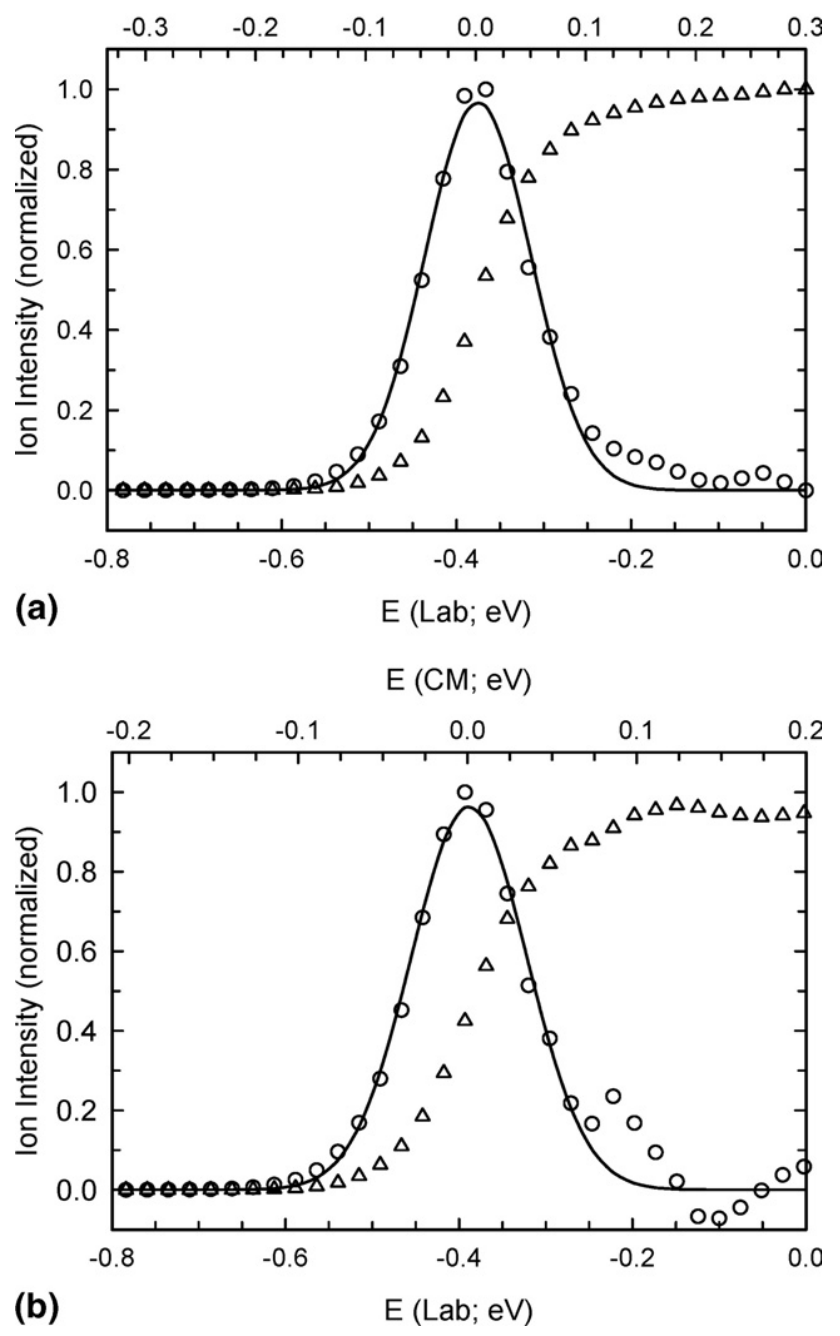

Figure 6. Kinetic energy profile for (a) $\mathrm{H}_{3} \mathrm{O}^{+}\left(\mathrm{H}_{2} \mathrm{O}\right)_{2}$ and (b) $\mathrm{Na}^{+}$(proline), shown in the laboratory frame (lower $x$-axis) and center-of-mass frame (upper $x$-axis, assuming Xe collision gas). Open triangles $(\triangle)$ show the normalized ion intensity versus DC voltage on the octopole near the zero of energy. For both (a) and (b), the maximum ion intensity was about $1 \times 10^{6}$ ions/s. Open circles $(\bigcirc)$ are the first derivative of the ion intensity. Solid lines show the best fit to a Gaussian distribution. For (a) $E_{0}=-0.375$ $\mathrm{eV}, \mathrm{FWHM}=0.143 \mathrm{eV}(\mathrm{Lab}) ;(\mathbf{b}) E_{0}=-0.388 \mathrm{eV}, \mathrm{FWHM}=0.157$ $\mathrm{eV}(\mathrm{Lab})$.

or on the rf frequency of the $6 \mathrm{P}$ from 4 to $6 \mathrm{MHz}$. In Figure ${ }^{\circ} 6$, the ${ }^{\circ}$ voltage ${ }^{\circ}$ drop between ${ }^{\circ}$ the ${ }^{\circ} F^{\circ}{ }^{\circ}{ }^{\circ}{ }^{\circ} 6 \mathrm{P}^{\circ}$ was 7 and $1 \mathrm{~V}$ for the $\mathrm{Na}^{+}$(proline) and $\mathrm{H}_{3} \mathrm{O}^{+}\left(\mathrm{H}_{2} \mathrm{O}\right)_{2}$ systems, respectively; nevertheless the $\mathrm{KE}_{0}$ in both cases remains at about $0.38 \mathrm{~V}$. This reiterates that ions injected into the 5.5-in.-long 6P quickly undergo sufficient collisions to kinetically equilibrate. One advantage of such equilibration is that it allows for conditions in the IF to be adjusted to generate different ion distributions for analysis without concern that optimal conditions for production of the ions could lead to non-thermal internal energy distributions for analysis.

\section{Thermalization}

Figure $\% \mathrm{a}^{\circ}$ and $\mathrm{b}$ show ${ }^{\circ}$ xample ${ }^{\circ}$ ressure ${ }^{\circ}$ xtrapolated ${ }^{\circ}$ cross sections for $\mathrm{H}_{3} \mathrm{O}^{+}\left(\mathrm{H}_{2} \mathrm{O}\right)_{2}$ and $\mathrm{Na}^{+}$(proline), respectively, produced using the ESI/IF/6P source. These figures also include the corresponding convoluted and unconvoluted fits to eq 1 . The experimental cross sections are reproduced by eq 1 over a large range of collision energies (2-4 $\mathrm{eV})$, over at least a factor of 100 in magnitude and within an absolute cross section of about $0.1 \times 10^{-16} \mathrm{~cm}^{2}$.

Table $^{\circ} 1^{\circ}$ shows $^{\circ} \mathrm{TCID}^{\circ}$ results $^{\circ}$ for ${ }^{\circ}$ ions ${ }^{\circ}$ produced ${ }^{\circ}$ by ${ }^{\circ}$ the $\mathrm{ESI} / \mathrm{IF} / 6 \mathrm{P}$ source compared to a number of DC/FT studies $^{\circ}$ performed ${ }^{\circ}$ by $^{\circ}$ this ${ }^{\circ}{ }$ lab $^{\circ}$ for ${ }^{\circ}$ the ${ }^{\circ} \mathrm{Na}^{+}$(proline) $)^{\circ}[17]^{\circ}$ and $\mathrm{H}_{3} \mathrm{O}^{+}\left(\mathrm{H}_{2} \mathrm{O}\right)_{x}\left(x={ }^{\circ} 1-3\right)^{\circ}\left[15,{ }^{\circ} 41\right]^{\circ}$ systems. ${ }^{\circ}$ All ${ }^{\circ}$ of ${ }^{\circ}$ the ${ }^{\circ} \mathrm{TCID}$ results in the table include pressure extrapolations and RRKM $^{\circ}$ corrections $^{\circ}$ as $^{\circ}$ described $^{\circ}$ earlier..$^{\circ}$ Table $^{\circ} 1^{\circ}$ also ${ }^{\circ}$ in-
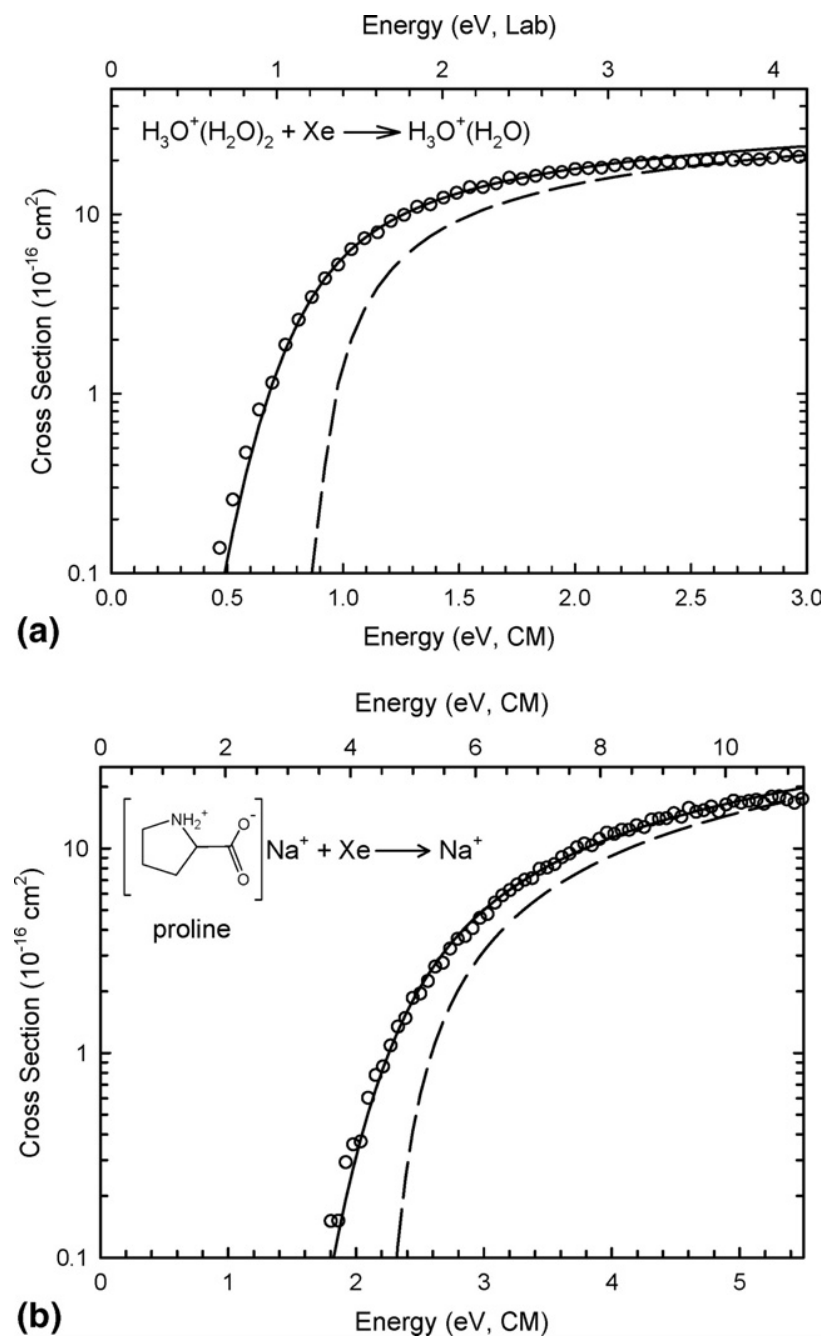

(b)

Energy (eV, CM)

Figure 7. Zero-pressure extrapolated cross sections for collisioninduced dissociation of $(\mathbf{a}) \mathrm{H}_{3} \mathrm{O}^{+}\left(\mathrm{H}_{2} \mathrm{O}\right)_{2}$ and (b) $\mathrm{Na}^{+}$(proline) with $\mathrm{Xe}$ in the threshold region as a function of kinetic energy in the center-of-mass frame (lower $x$-axis) and the laboratory frame (upper $x$-axis). Solid lines show the best fit to the data using the model of eq 1 convoluted over the neutral and ion kinetic and internal energy distributions. Dashed lines show the model cross sections in the absence of experimental kinetic energy broadening for reactions with an internal energy of $0 \mathrm{~K}$. 
Table 1. Comparison of ESI TCID results with fitting parameters for eq 1

\begin{tabular}{|c|c|c|c|c|c|}
\hline System & Source & $\sigma_{0}$ & $n$ & $E_{0}(\mathrm{eV})$ & $\begin{array}{c}E_{0} \\
\text { literature }\end{array}$ \\
\hline \multirow[t]{2}{*}{$\mathrm{Na}^{+}$(proline $) \rightarrow \mathrm{Na}^{+}+$proline } & $\mathrm{ESI} / \mathrm{IF} / 6 \mathrm{P}^{\mathrm{a}}$ & $15.9(1.0)$ & $1.5(0.1)$ & $1.94(0.08)$ & $2.01(0.08)^{d}$ \\
\hline & $\mathrm{DC} / \mathrm{FT}^{\mathrm{b}}$ & $15.4(1.0)$ & $1.4(0.1)$ & $1.93(0.06)$ & $1.80(0.12)^{\mathrm{e}}$ \\
\hline \multirow[t]{2}{*}{$\mathrm{H}_{5} \mathrm{O}_{2}^{+} \rightarrow \mathrm{H}_{3} \mathrm{O}^{+}+\mathrm{H}_{2} \mathrm{O}$} & $\mathrm{ESI} / \mathrm{IF} / 6 \mathrm{P}^{\mathrm{a}}$ & $5.6(0.4)$ & $1.5(0.2)$ & $1.44(0.06)$ & $\begin{array}{l}1.37(0.04)^{f} \\
1.65(0.10)^{\mathrm{f}} \\
1.62(0.08)^{\mathrm{h}}\end{array}$ \\
\hline & $\mathrm{DC} / \mathrm{FT}^{\mathrm{c}}$ & $4.0(0.2)$ & $1.5(0.1)$ & $1.40(0.04)$ & $\begin{array}{c}1.4(0.1)^{\mathrm{i}} \\
1.24(0.09)^{\mathrm{j}}\end{array}$ \\
\hline \multirow[t]{2}{*}{$\mathrm{H}_{7} \mathrm{O}_{3}^{+} \rightarrow \mathrm{H}_{5} \mathrm{O}_{2}^{+}+\mathrm{H}_{2} \mathrm{O}$} & $\mathrm{ESI} / \mathrm{IF} / 6 \mathrm{P}^{\mathrm{a}}$ & $25.8(1.4)$ & $1.2(0.1)$ & $0.88(0.05)$ & $\begin{array}{l}0.85(0.04)^{f} \\
0.90(0.10)^{g}\end{array}$ \\
\hline & $\mathrm{DC} / \mathrm{FT}^{\mathrm{c}}$ & $18.6(0.8)$ & $1.5(0.2)$ & $0.89(0.06)$ & $\begin{array}{l}0.96(0.04)^{\mathrm{h}} \\
0.82(0.04)^{\mathrm{k}}\end{array}$ \\
\hline \multirow[t]{2}{*}{$\mathrm{H}_{9} \mathrm{O}_{4}^{+} \rightarrow \mathrm{H}_{7} \mathrm{O}_{3}^{+}+\mathrm{H}_{2} \mathrm{O}$} & $\mathrm{ESI} / / \mathrm{F} / 6 \mathrm{P}^{\mathrm{a}}$ & $37.9(2.8)$ & $1.0(0.1)$ & $0.72(0.05)$ & $\begin{array}{l}0.72(0.04)^{\mathrm{g}} \\
0.77(0.05)^{\mathrm{h}}\end{array}$ \\
\hline & $\mathrm{DC} / \mathrm{FT}^{\mathrm{c}}$ & $38.6(2.0)$ & $1.2(0.3)$ & $0.73(0.06)$ & $\begin{array}{l}0.69(0.04)^{\mathrm{k}} \\
0.78(0.04)^{1}\end{array}$ \\
\hline
\end{tabular}

ESI, electrospray ionization source; TCID, threshold collision-induced dissociation; DC/FT, DC discharge/flow tube source; HPMS, high-pressure mass spectrometry; KM, kinetic method; ICR EQ, ion cyclotron resonance equilibrium.

a This work.

bTCID, DC/FT [17].

'TCID, DC/FT [15].

${ }^{\mathrm{d}} \mathrm{KM}[41]$.

ICR EQ [42].

fHPMS [43].

9TCID [44].

hTCID [45]

iESI, TCID [2].

jESI, TCID [5] ( $E_{0}$ converted from $298 \mathrm{~K}$ value using standard thermodynamic formulas).

kHPMS [46].

'HPMS [47].

cludes threshold values produced using other sources and experimental ${ }^{\circ}$ methodologies ${ }^{\circ}\left[2,{ }^{\circ} 5,{ }^{\circ} 41-47\right] .{ }^{\circ}$ For $^{\circ}$ all ${ }^{\circ}$ of ${ }^{\circ}$ the systems shown in Table 1, the ESI/IF/6Presults produced using the ${ }^{\circ}$ configuration ${ }^{\circ}$ shown ${ }^{\circ}{ }^{\circ}$ Figure 19 yield ${ }^{\circ}$ threshold energies well within stated experimental uncertainties of the previous results. There is particularly excellent agreement for the magnitude of the cross section $\left(\sigma_{0}\right)$, shape of the cross section $(n)$, and the threshold value $\left(E_{0}\right)$ between the TCID results produced in this lab using the DC/FT and ESI/IF/6P sources. Threshold values produced by the ESI/IF/6P source show such agreement over a $>1-e V$ range of threshold values $(0.7-1.9 \mathrm{eV})$ and for systems with $m / z$ values ranging from 37 to $138 \mathrm{Da}$.

As with the kinetic energy distributions, the source is surprisingly robust to changes in conditions. Adjustments to the 6P parameters over ranges varying from 200 to 400 Vpp and 4 to $6 \mathrm{MHz}$ do not produce any observable changes to the extracted threshold energies. Similarly, conditions in the IF or desolvation temperature of the CTH have no impact on measured threshold values. It is believed that this is primarily a consequence that the pressure in the source chamber under operating conditions is sufficiently high (20-40 mTorr) that the ions undergo many collisions before they diffuse to the exit of the $6 \mathrm{P}$. A rough calculation of the average number of collisions undergone by a $\mathrm{Na}^{+}$(proline) ion diffusing from the entrance of the $6 \mathrm{P}$ to the next chamber is $>10^{4}$, more than enough to ensure thermalization.

\section{Conclusions}

The electrospray source described here meets all four requirements necessary for rigorous thermochemical analysis: high signal intensity, signal stability, welldefined kinetic energy distributions, and ions with internal energies described by a Maxwell-Boltzmann distribution at room temperature. The use of an ion funnel with a jet disrupter and hexapole ion guide in series takes advantage of the intrinsic properties of both devices to collect, transfer, and thermalize ions emerging from the electrospray. Using either device alone can lead to poorly defined ion characteristics. The source is also extremely robust to changes in experimental parameters. The addition of the ESI source to the GIBMS opens the door for thermochemical analysis of a wide range of new and interesting systems for study. For example, TCID results for the hydration energies of multiply charged ions such as $\mathrm{Ca}\left(\mathrm{H}_{2} \mathrm{O}\right)_{x}{ }^{2+}(x=5-9)$ show good agreement with previous literature values and ${ }^{\circ}$ with ${ }^{\circ}$ theory ${ }^{\circ}[48]$, but ${ }^{\circ}$ preliminary ${ }^{\circ}{ }^{\circ}$ esults ${ }^{\circ}$ show ${ }^{\circ}$ that the hydration energies of the inner solvent shell $(x=$

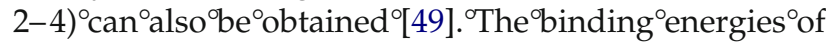
alkali $^{\circ}$ cations ${ }^{\circ}$ to $^{\circ}$ cysteine $^{\circ}[50],{ }^{\circ}$ the ${ }^{\circ}$ acidic $^{\circ}$ amino ${ }^{\circ}$ acids (aspartic acid and glutamic acid), and their amide derivatives $^{\circ}\left(\right.$ asparagine $^{\circ}$ and $^{\circ}$ glutamine $^{\circ}[51]^{\circ}$ have $^{\circ}$ been measured using this source and show good agreement with theory. Extensions to metallized di- and tripep- 
tides ${ }^{\text {have }}{ }^{\circ}$ also ${ }^{\text {been }}{ }^{\circ}$ achieved ${ }^{\circ}{ }^{\text {with }}{ }^{\circ}$ good $^{\circ}{ }^{\text {results }}[24,29$, 52].

\section{Acknowledgments}

This work was funded by National Science Foundation Grant CHE0451477. A portion of the research reported herein was performed under user proposal \#2223 in the Environmental Molecular Sciences Laboratory (EMSL) located at Pacific Northwest National Laboratory (PNNL). RMM thanks Keqi Tang and SangWong Lee for their generous advice. The assistance of the University of Utah Department of Chemistry machine shop (Dennis Romney and Jeff Welch) and electronics shop (Ron Jones) was invaluable in the development of this instrument.

\section{References}

1. Yamashita, M.; Fenn, J. B. Electrospray Ion Source. Another Variation on the Free-jet Theme. J. Phys. Chem. 1984, 88, 4451-4459.

2. Andersen, S. G.; Blades, A. T.; Klassen, J. S.; Kebarle, P. Determination of Ion-Ligand Bond Energies and Ion Fragmentation Energies of Electrospray-produced Ions by Collision-induced Dissociation Threshold Measurements. Int. J. Mass Spectrom. Ion Process. 1995, 141, 217-228.

3. Poutsma, J. C.; Seburg, R. A.; Leonard, J. C.; Sunderlin, L. S.; Hill, B. T.; $\mathrm{Hu}$, J.; Squires, R. R. Combining Electrospray Ionization and the Flowing Afterglow Method. Rapid Commun. Mass Spectrom. 1997, 11, 487-493.

4. Klassen, J. S.; Anderson, S. G.; Blades, A. T.; Kebarle, P. Reaction Enthalpies for $\mathrm{M}^{+} \mathrm{L}=\mathrm{M}^{+}+\mathrm{L}$, Where $\mathrm{M}^{+}=\mathrm{Na}^{+}$and $\mathrm{K}^{+}$and $\mathrm{L}=$ Acetamide, N-Methylacetamide, N,N-Dimethylacetamide, Glycine, and Glycylglycine, from Determinations of the Collision-induced Dissociation Thresholds. J. Phys. Chem. 1996, 100, 14218-14227.

5. Hinderling, C.; Feichtinger, D.; Plattner, D. A.; Chen, P. A Combined Gas-Phase, Solution-Phase and Computational Study of C-H Activation by Cationic Iridium(III) Complexes. J. Am. Chem. Soc. 1997, 119, 1079310804

6. Ho, Y.; Kebarle, P. Studies of the Dissociation Mechanisms of Deprotonated Mononucleotides by Energy Resolved Collision-induced Dissociation. Int. J. Mass Spectrom. Ion Process. 1997, 165/166, 433-455.

7. Crain, P. F. Electrospray Ionization Mass Spectrometry of Nucleic Acids and Their Constituents. In Electrospray Ionization Mass Spectrometry: Fundamentals Instrumentation and Applications, Cole, R. B., Ed.; John Wiley \& Sons: New York, 1997; pp 421-457.

8. Loo, J. A.; Ogorzsalek Loo, R. R. Electrospray Ionization Mass Spectrometry of Peptides and Proteins. In Electrospray Ionization Mass Spectrometry: Fundamentals Instrumentation and Applications, Cole, R. B., Ed.; John Wiley \& Sons: New York, 1997; pp 385-419.

9. Ohashi, Y. Electrospray Ionization Mass Spectrometry of Carbohydrates and Lipids. In Electrospray Ionization Mass Spectrometry: Fundamentals Instrumentation and Applications, Cole, R. B., Ed.; John Wiley \& Sons: New York, 1997; pp 459-498.

10. Gatlin, C. L.; Turecek, F. Acidity Determiniation in Droplets Formed by Electrospraying Methanol-Water Solutions. Anal. Chem. 1994, 66, 712718.

11. Van Berkel, G. J.; McLuckey, S. A.; Glish, G. L. Electrochemical Origin of Radical Cations Observed in Electrospray Ionization Mass Spectra. Anal. Chem. 1992, 64, 1586-1593.

12. Gatlin, C. L.; Turecek, F. Electrospray Ionization of Inorganic and Organometallic Complexes. In Electrospray Ionization Mass Spectrometry: Fundamentals Instrumentation and Applications, Cole, R. B., Ed.; John Wiley \& Sons: New York, 1997; pp 527-570.

13. Sherman, C. L.; Brodbelt, J. S. An Equilibrium Partitioning Model for Predicting Response to Host-Guest Complexation in Electrospray Ionization Mass Spectrometry. Anal. Chem. 2003, 75, 1828-1836.

14. Kempen, E. C.; Brodbelt, J. S.; Bartsch, R. A.; Jang, Y.; Kim, J. S. Investigation of Alkali Metal Cation Selectivities of Lariat Ethers by Electrospray Ionization Mass Spectrometry. Anal. Chem. 1999, 71, 54935550.

15. Dalleska, N. F.; Honma, K.; Armentrout, P. B. Stepwise Solvation Enthalpies of Protonated Water Clusters: Collision Induced Dissociation as an Alternative to Equilibrium Studies. J. Am. Chem. Soc. 1993, 115, 12125-12131.

16. Moision, R. M.; Armentrout, P. B. An Experimental and Theoretical Dissection of Sodium Cation/Glycine Interactions. J. Phys. Chem. A 2002, 106, 10350-10362.

17. Moision, R. M.; Armentrout, P. B. The Special Five-Membered Ring of Proline: An Experimental and Theoretical Investigation of Alkali Metal Cation Interactions with Proline and Its Four- and Six-Membered Ring Analogues. J. Am. Chem. Soc. 2006, 110, 3933-3946.

18. Amicangelo, J. C.; Armentrout, P. B. Absolute Binding Energies of Alkali-Metal Cations with Benzene Determined by Threshold Collisioninduced Dissociation Experiments and Ab Initio Theory. J. Phys. Chem. A 2000, 104, 11420-11432.
19. Schultz, R. H.; Armentrout, P. B. Reactions of $\mathrm{N}_{4}{ }^{+}$with Rare Gases from Thermal to $10 \mathrm{eV}$ c.m.: Collision-induced Dissociation, Charge Transfer, and Ligand Exchange. Int. J. Mass Spectrom. Ion Process. 1991, 107, 29-48.

20. Muntean, F.; Armentrout, P. B. Guided Ion Beam Study of Collisioninduced Dissociation Dynamics: Integral and Differential Cross Sections. J. Chem. Phys. 2001, 115, 1213-1228.

21. Ervin, K. M.; Armentrout, P. B. Translational Energy Dependence of $\mathrm{Ar}^{+}+\mathrm{XY} \rightarrow \mathrm{ArX}^{+}+\mathrm{Y}\left(\mathrm{XY}=\mathrm{H}_{2}, \mathrm{D}_{2}, \mathrm{HD}\right)$ from Thermal to $30 \mathrm{eV}$ c.m. J. Chem. Phys. 1985, 83, 166-189.

22. Teloy, E.; Gerlich, D. Integral Cross Sections for Ion-Molecule Reactions. 1. The Guided Beam Technique. Chem. Phys. 1974, 4, 417-427.

23. Gerlich, D. Inhomogeneous rf Fields: A Versatile Tool for the Study of Processes with Slow Ions. Adv. Chem. Phys. 1992, 82, 1-176.

24. Schultz, R. H.; Armentrout, P. B. Threshold Collisional Activation of $\mathrm{FeC}_{2} \mathrm{H}_{6}{ }^{+}: \mathrm{Fe}^{+}$. ethane vs. $\mathrm{Fe}^{+}$. dimethyl Structures. J. Phys. Chem. 1992, 96, 1662-1667.

25. Rodgers, M. T. Substituent Effects in the Binding of Alkali Metal Ions to Pyridines Studied by Threshold Collision-induced Dissociation and $\mathrm{Ab}$ Initio Theory: The Aminopyridines. J. Phys. Chem. A 2001, 105, 81458153.

26. Rodgers, M. T.; Armentrout, P. B. An Absolute Sodium Cation Affinity Scale: Threshold Collision-induced Dissociation Experiments and $\mathrm{Ab}$ Initio Theory. J. Phys. Chem. A 2000, 104, 2238-2247.

27. Amunugama, R.; Rodgers, M. T. The Influence of Substituents on Cation- $\pi$ Interactions. 1. Absolute Binding Energies of Alkali Metal Cation-Toluene Complexes Determined by Threshold Collision-induced Dissociation and Theoretical Studies. J. Phys. Chem. A 2002, 106 , 5529-5539.

28. Armentrout, P. B. Thermochemical Measurements by Guided Ion Beam Mass Spectrometry. In Advances in Gas Phase Ion Chemistry, Adams, N. G.; Babcock, L. M., Eds.; JAI Press: Greenwich, CT, 1992; Vol. 1, pp 83-119.

29. Chantry, P. J. Doppler Broadening in Beam Experiments. J. Chem. Phys. $1971,55,2746-2759$.

30. Lifshitz, C.; Wu, R. L. C.; Tiernan, T. O.; Terwilliger, D. T. Negative Ion-Molecule Reactions of Ozone and Their Implications on the Thermochemistry of $\mathrm{O}_{3}{ }^{-}$. J. Chem. Phys. 1978, 68, 247-260.

31. Rodgers, M. T.; Ervin, K. M.; Armentrout, P. B. Statistical Modeling of Collision-induced Dissociation Thresholds. J. Chem. Phys. 1997, 106 4499-4508.

32. Shaffer, S. A.; Prior, D. C.; Anderson, G. A.; Udseth, H. R.; Smith, R. D. An Ion Funnel Interface for Improved Ion Focusing and Sensitivity Using Electrospray Ionization Mass Spectrometry. Anal. Chem. 1998, 70, 4111-4119.

33. Shaffer, S. A.; Tolmachev, A.; Prior, D. C.; Anderson, G. A.; Udseth, H. R.; Smith, R. D. Characterization of an Improved Electrodynamic Ion Funnel Interface for Electrospray Ionization Mass Spectrometry. Anal. Chem. 1999, 71, 2957-2964.

34. Belov, M. E.; Gorshkov, M. V.; Udseth, H. R.; Anderson, G. A.; Smith R. D. Zeptomole-Sensitivity Electrospray Ionization-Fourier Transform Ion Cyclotron Resonance Mass Spectrometry of Proteins. Anal. Chem. 2000, 72, 2271-2279.

35. Kim, T.; Udseth, H. R.; Smith, R. D. A Multicapillary Inlet Jet Disruption Electrodynamic Ion Funnel Interface for Improved Sensitivity Using Atmospheric Pressure Ion Sources. Anal. Chem. 2001, 73, 4162-4170.

36. Tang, K.; Tolmachev, A.; Nikolaev, E.; Zhang, R.; Belov, M. E.; Udseth, H. R.; Smith, R. D. Independent Control of Ion Transmission in a Jet Disrupter Dual-Channel Ion Funnel Electrospray Ionization MS Interface. Anal. Chem. 2002, 74, 5431-5437.

37. Rodgers, M. T.; Armentrout, P. B. Absolute Binding Energies of Sodium Ions to Short Chain Alcohols Determined by Threshold Collisioninduced Dissociation Experiments and Ab Initio Theory. J. Phys. Chem. A 1999, 103, 4955-4963.

38. Jones, R. M.; Anderson, S. L. Simplified Radio-Frequency Generator for Driving Ion Guides, Traps and Other Capacitive Loads. Rev. Sci. Instrum. 2000, 71, 4335-4337.

39. Jones, R. M.; Gerlich, D.; Anderson, S. L. Simple Radio-Frequency Power Source for Ion Guides and Ion Traps. Rev. Sci. Instrum. 1997, 68, 3357-3362.

40. Manura,, D. A Hard-Sphere, Elastic, Ion-Neutral Collision Model for SIMION. Available at collision hs1.prg rev. 2-2005-07-13. Scientific Instrument Services, Inc., Ringoes, NJ: 2006.

41. Kish, M. M.; Ohanessian, G.; Wesdemiotis, C. The $\mathrm{Na}^{+}$Affinities of $\alpha$-Amino Acids: Side-chain Substituent Effects. Int. J. Mass Spectrom. 2003, 227, 509-524.

42. Gapeev, A.; Dunbar, R. C. $\mathrm{Na}^{+}$Affinities of Gas-phase Amino Acids by Ligand Exchange Equilibrium. Int. J. Mass Spectrom. 2003, 228, 825-839.

43. Cunningham, A. J.; Payzant, A. D.; Kebarle, P. Kinetic Study of the Proton Hydrate $\mathrm{H}^{+}\left(\mathrm{H}_{2} \mathrm{O}\right)_{\mathrm{n}}$ Equilibriums in the Gas Phase. J. Am. Chem. Soc. 1972, 94, 7627-7632.

44. Honma, K.; Sunderlin, L. S.; Armentrout, P. B. Reactions of Protonated Water Clusters with Deuterated Ammonia $\mathrm{H}\left(\mathrm{H}_{2} \mathrm{O}\right)_{\mathrm{n}}{ }^{+}(\mathrm{n}=1-4)+\mathrm{ND}_{3}$. Int. J. Mass Spectrom. Ion Process. 1992, 117, 237-259.

45. Honma, K.; Sunderlin, L. S.; Armentrout, P. B. Guided-ion Beam Studies of the Reactions of Protonated Water Clusters, $\mathrm{H}\left(\mathrm{H}_{2} \mathrm{O}\right)_{n}{ }^{+}(\mathrm{n}=1-4)$. J. Chem. Phys. 1993, 99, 1623-1632.

46. Meot-Ner, M.; Speller, C. V. Filling Solvent Shells about Ions. 1. Thermochemical Criteria and the Effects of Isomeric Clusters. J. Phys. Chem. 1986, 90, 6616-6624. 
47. Lau, Y. K.; Ikuta, S.; Kebarle, P. Thermodynamics and Kinetics of the Gas-phase Reactions $\mathrm{H}_{3} \mathrm{O}^{+}\left(\mathrm{H}_{2} \mathrm{O}\right)_{n-1}+$ Water $=\mathrm{H}_{3} \mathrm{O}^{+}\left(\mathrm{H}_{2} \mathrm{O}\right)_{n}$. J. Am. Chem. Soc. 1982, 104, 1462-1469.

48. Carl, D.; Moision, R. M.; Armentrout, P. B. Binding Energies for the Inner Hydration Shells of $\mathrm{Ca}^{2+}$ : An Experimental and Theoretical Investigation of $\mathrm{Ca}^{2+}\left(\mathrm{H}_{2} \mathrm{O}\right)_{x}$ Complexes $(x=5-9)$. Int. J. Mass Spectrom., accepted for publication.

49. Carl, D.; Moision, R. M.; Armentrout, P. B. Binding Energies for the Innermost Hydration Shell of $\mathrm{Ca}^{2+}$ : An Experimental and Theoretical Investigation of $\mathrm{Ca}^{2+}\left(\mathrm{H}_{2} \mathrm{O}\right)_{x}$ Complexes $(x=1-4)$. Work in progress.
50. Ye, S. J.; Moision, R. M.; Armentrout, P. B. Alkali Cation Binding Energies to Cysteine: Threshold Collision-induced Dissociation and Theoretical Studies. Work in progress.

51. Heaton, A. L.; Moision, R. M.; Armentrout, P. B. Binding Energies of the Alkali Cations to the Acidic Amino Acids (Asp, Glu), Their Amide Derivatives (Asn, Gln), and Their Dehydration/Deamidation Fragments: Theory and Experiment. Work in progress.

52. Ye, S. J.; Moision, R. M.; Armentrout, P. B. Threshold Collision Induced Dissociation Studies of the Binding Energies of Alkali Cations to Small Peptides: Gly-Gly and Gly-Gly-Gly. Work in progress. 